\title{
Decir identidad
}

LUIS ERNESTO LASSO

En momentos del Plan Colombia -signado hasta por Kinssinger de belicistacomo forma específica de la globalización, recuperar la acomodaticia pala IDENTIDAD para tratar de situarla convenientemente en el debate que promulga la resistencia a las agresiones desdibujadoras del ser y de la vida en su diversidad, es obligación de todo ser pensante. Aquí van retomados intentos que buscan servir de pertrecho en el tiempie de las definiciones que nos impelen a tomar.

\section{1. "Circunstancia de ser efectlvamente una persona lo que dice ser"}

Larousse

Sin más, en el trajín de la cotidianidad hos encontramos con esta aseveración que solemos olvidar a la hora de los ontologismos, cuando se llega a puntualizaciones como ésta: "lo que es, es y lo que no es, no es". Pareciera que en Perogrullo tautológico, encontrames la superación de las inmensas entidades para conformar perfiles.

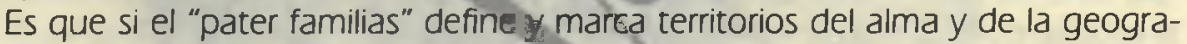
fía, otro tanto ha ocurrido con el poder ie los tiranos - de Grecia o de donde se ejecuta el poder onmímodo- moldeando los contornos griegos, o formando los emperadores romanos las siluetas del paeblo italo la efigie del dominio imperante. Y así en el devenir: la civilización occidental se reconoce en las diversas manifestaciones europeas donde se ha hecho una, la terrible vislumbre de Montaigne tocando a los aborígenes de Nuestra Ninérica: "...nos hemos servido de su ignorancia e inexperiencia, para inclinarlos más fácilmente a la traición, a la lujuria, a la avaricia y a toda suerte de inhumanidad y crueldad, a ejemplo y modo de nuestras costumbres"'.

Seguramente el bretón estaba pensando en la sangre derramada por el pretexto de la veleidosa Helena, tanto como la que vertieran en las guerras impe- 
riales o en las de cristiandad para imponer-como luego en América- a cruz y espada, la religión, de inicio pacífica e igualitaria, como que provenía de pescadores sojuzgados y perseguidos. Y eso que no alcanzó a conocer la conquista que occidente hizo de África y Asia, ni de los muros de sangre que construyera Hitler y demás monismos sucesivos.

Es cuando cabe preguntarse: ¿Qué han sido los europeos a lo largo de su penoso devenir? LQué son hoy como individuos y colectividad, cuando les imponen el neofascismo en todas sus formas? ¿Lo que postulan austriacos, israelitas, alemanes y españoles en el mando central va en contravía de las recientes lecciones históricas que padecieron sus pueblos? ¿Las individualidades y pequeñas organizaciones que contradicen estas evidencias, no contarán-como siempre- para alarmar al conjunto de la Unión Europea?.

Sambarino ${ }^{2}$ nos recuerda que la preocupación identitaria se hace corriente en Europa desde Rosseau, para esplender con Nietszche y después con los existencialistas. Antes nos ha dado gran aporte: no hay identidad sino en relación con los otros. Como para que aceptemos que en periodos de crisis -prerrevolución francesa burguesa, desencanto del mundo y advenimiento de la sociedad socialista- el autismo social se revienta y los hombres emprenden la comunicación para que florezca la solidaridad por las causas comunes. Lastimosamente sólo una minoría que no logra desalojar del dominio a la otra minoría que siempre impone la uniformidad, el señalamiento de la diferencia como perversión, se entera, se esfuerza, sucumbe, permaneciendo siempre idéntica en sus aspiraciones de utopía.

Ahora ya casi podríamos deducir que el criterio de identidad -ser uno para poder socializarse con las causas comunes de autenticidad- se constituye en períodos revolucionarios como égida de los impulsadores de la historia, que poco logran hacerse al dominio social para remover desde la base lo que desidentifica al ser humano, convirtiéndolo en subalterno de los deshumanizadores del poder devorador.

\section{2. "Somos un pequeño género humano"}

\section{Simón Bolívar}

Justamente, en plena guerra independentista -y derrotado en Jamaicael libertador habría de calar nuestra particularidad, como tal vez nadie más lo ha logrado: ni europeos, ni americanos, "más bien un compuesto de África y América (...). Es imposible asignar con propiedad a qué familia humana pertenecemos". Un poco más adelante detectaría lo conflictivo del hallazgo: "esta diferencia trae un reto de la mayor trascendencia", dice y aún no lo asumimos.

Porque a ese reto no se llega por reduccionismos: el sarmientino - "Seamos Los Estados Unidos", o el de Bilbao culpando la colonia española que nos anonada, lo mismo que la postura del chovinista del intonso que postula el regreso a la arcadía indígena, como la manera de superar el abigarrado problema. Superando desdenes hegelianos, desprecios de Marx, ver-

2 Identidad, tradición, autenticidad, Tres problemas de América Latina. Caracas, Rómulo Gallegos, 1980. 
güenzas darianas, desaires borgesianos- "ser colombiano es un acto de fe" -José Carlos Mariátegui lejos de regionalismos hirsutos- se acerca al carácter formativo de nuestra identidad:

“...el espíritu hispanoamericano está en elaboración (...). Aquí las síntesis no existe todavía. Los elementos de la nacionalidad no han podido fundirse o soldarse"3.

A su vez, el referido Sambarino precisa la urgencia de la construcción: sobre mezclas y préstamos no se construye identidad -dice- sino sobre la remoción radical del tejido cultural, esto es, con los procesos revolucionarios que engendran un nuevo sistema. Y si la colonia persiste en nosotros, como observara Mariátegui; y si la neocolonia nos desfigura para ver en las encuestas que el $70 \%$ de los jóvenes quieren emigrar a Estados Unidos, su eje cultural; y si la intelectualidad del país sigue dando la espalda a la problemática en la hora más aciaga, para tejer sus fórmulas con la postmodernidad cínica y ahistórica emanada

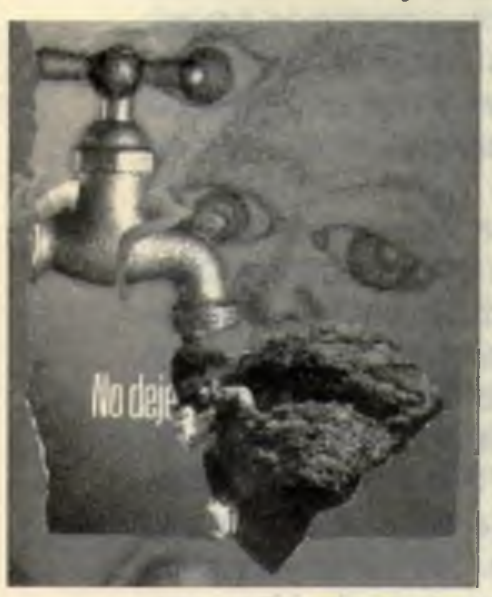
de la metrópolis, ¿con qué herramientas intentar la configuración de raíces, con qué colores bocetar nuestro rostro ante el universo?

Quienes pretenden asumir con entereza el reto son señalados por los uni- versalistas a ultranza como folcloristas, ignorando el postulado martiano que nos llega tan justo: "Injértese en nuestras repúblicas el mundo, pero el tronco ha de ser el nuestro". Lo que ocurre es que para los copistas miméticos intentar el encuentro de raices y el decantamiento de troncos es demasiada tarea. Si pensaran que sobre esas miras se construyeron la cultura griega, el teatro isabelino y la creación goethiana que fundaron pueblos, tal vez su inteligencia se aplicaría a las metas comunes. No en vano Unamuno sintetiza con propiedad: "Hemos de hallar lo universal en las entrañas de lo local, y en lo limitado y circunstancial, lo eterno"; lo que hace más contundente el guatemalteco Cardoza y Aragón al concretar: "La Dulcinea, para ser universal, era ante todo del Toboso".

En 1974. Sebastián Salazar Bondy ya había hecho extensivo al plano de la cultura espiritual el principio moderno que regula las relaciones de los seres: la relatividad. En ese sentido advierte que los valores que se impusieron como universales tenían sabor netamente europeo y occidental, "mera definición del centro del poder mundial que se imponía a la periferia", para concluir acertadamente:

Para legar a la universalidad de la filosofía no debemos ponernos en la línea del universalismo occidental, porque es una manera de remedar y no de hacer filosofía, y esto que estoy diciendo en términos de filosofía, creo que se podría decir en términos de educación, en términos de arte, de cultura y de instituciones también ${ }^{\prime \prime}$.

\footnotetext{
3 "El proceso de la cultura Latinoamericana: 1898-1930" en Casa de Las Américas, No. 118, La Habana.

4 Textual No. 9. Lima 1974, dedicada a Salazar Bondy.
} 
Paradójicamente, un destacado francés habría de alentarnos en esta ardua labor de contrastar la globalización post-modernista que busca barrer la diferencia para uniformar, como en el medioevo, a quienes propendan por la humanización. Dice así Jack Lang: “Cuidémonos de cultivar sincretismos fofos y borrosos. Y, en cambio, estemos orgullosos de nuestras identidades y de nuestras particularidades y miremos con admiración el espectáculo de nuestras diferencias" ${ }^{\prime 5}$ - A su vez, desde esta orilla, Jaime Labastida proclamaría la "Eclosión de la Diferencia", sentada en precisiones indescartables:

Hay quienes quieren definir lo que somos exclusivamente sobre la base del pasado (...). Pero el caso es que somos aquello que deseamos ser (...).

El investigador radicaliza el pensamiento para llevarlo al clasismo, lo que aterra a los loros parlanchines del fin de la ideología, el acabóse de la historia: "La modernidad está en la clase obrera (...). Suya es también la cultura y el sentido profundo de una identidad nueva, diferente"'.

Por supuesto que el estudioso argentino sabía de la farsa a derrumbar del "socialismo real" y de los burocratismos que siguen asolando la mentalidad de la clase más avanzada de la sociedad. Mas su postura es consecuente con el aserto de ver la identidad en lo desiderativo, en el futuro por recuperar, máxime hoy que nos intentan hacer creer que no existen horizontes.

En el mismo sendero se ubican los filósofos de la liberación -Ardao. García, Krauza, Palazón, Zea, etc- -que ya son identificados en la misma Eu- ropa por esa distintividad que coincide con los poetas y narradores de Nuestra América, quienes desde el siglo XX han recuperado lo más avanzado de nuestra mismidad, hasta conformar una literatura mayor que se define por perfiles autóctonos en busca del ser latinoamericano, a la vez que se inserta en la más rica expresión de las letras universales.

\section{3. "En Colombia no hay cultura porque todo es mentira"} Antonio Caballero

Pueblo nuevo -que no testimonio, tal como lo clasifica Darcy Riveiro- el de Colombia aún carece de momento fundacional. Sin alta cultura aborigen, con una colonia tipificada en la "olla podrida" de El Carnero, con una revuelta comunera traicionada por el arzobispo que en pago fuera nombrado virrey, con una independencia gestada por Bolivar y los 13 llaneros supérstites.

Con un precursor Nariño acusado por connacionales que jamás levantaran la voz frente al domino español, con cientos de guerras internas para beneficios de los caudillos locales, con una Guerra de los Mil Días que hiciera nacer a Panamá para los gringos y un estado godificante sin matices, con una guerra que no cesa desde el "bogotazo", para consolidar la oligarquía bipartidista siempre "arrodillada ante el amo yanqui", como dijera Gaitán, ¿de dónde aferrarse para la reconstrucción individual que prepare la formación de identidad nacional?

Decía Fernando Ortiz que "la gran tragedia histórica de las razas subyu- 
gadas es la de tener que negarse a sí mismas para sobrevivir, esconder el alma en lo más recóndito de la caverna para construir conductas de la más forzada nipocresía, de defensivos mimetismos, de dolorosísimas renunciaciones"7. Literalmente podríamos aplicar el texto a nuestra condición. donde el animal simbólico es el reptante y mimético lagarto, donde la virtud nacional impuesta a fuego en la década del 80 fue la delación. Un país con Concordato, primacía feroz de lo privado y religioso sobre lo público, donde las voces que salen del redil son suprimidas - de Uribe Uribe a Galtán, Galán, Pizarro o Gómez Hurtado; para recordar magnicidios que continúan impunes-, un país que jamás ha permitido ni posturas ni movimientos distintos del bipartidismo oligárquico, ¿con qué acto grande, digno, puede identificarse, reconstruirse?

Aníbal Quijano ${ }^{\circledR}$ señala cómo "la destrucción de las sociedades y culturas aborígenes implicó la condena de las poblaciones dominadas a ser integradas a un patrón de poder". Ese patrón de poder se configura en rasgos de desprecio al aborigen, distribución de identidades ligadas a los cambios de poder, poblaciones campesinas iletradas como colonizadas, seres impedidos de objetivar de modo autónomo sus propias imágenes, incapaces de ejercer sus facultades por fuera de los patrones dominantes, obligados a abandonar lo sagrado propio y admitir la condición deshonrosa de su propio imaginario, impelidos a imitar lo extraño, la mediocridad, lo banal, frente a lo propio mestizo donde podría estar "la genuina propuesta de recons- titución de identidad para la amplia mayoría de la población":

Los estudios del maestro Quijano para su Perú, con variantes ayudarían a entrevernos en un país donde jamás se sabe para quién se pelea ni mucho menos para qué, como sucedió al coronel Aureliano. Los esfuerzos de los artesanos (1853), los líderes aislados de populismos desviacionistas (ANAPO 1968) y de tanta guerrilla divorciada de la realidad y de los sectores populares, así como el sacrificio de sindicalistas, militantes civiles de organismos alternativos, en nada han servido para frenar la avalancha hegemónica sobre el resignado pueblo colombiano. Más de 2.5 millones de desterrados, 3.5 de desempleados, batallas de maestros y trabajadores de la salud por servicios que perderá toda la nación, no solidarizan ni a insurrectos ni a la masa enajenada que piden represión para quienes luchan por sus intereses: Más pueden "Betty La Fea", un partido de fútbol o los reinados del bambuco y de Cartagena.

\section{4. ¿Cuál tierra de promisión?}

El Huila que pariera la hegemonía espiritual conservadora nacida de la derrota liberal en la Guerra de los Mil Días, sólo ha incrementado el despropósito a lo largo de su devenir. Aquí sí que no ha pesado -ni en la USCO en sus 31 años- una lectura del mundo con lentes diversos a lo clerical, autoritario, clientelista, parroquial. Prácticamente no se ha intentado hacerlo, pese a que en la saga está la resistencia yalcona del invasor, el indio Toribio Zapata ensartando en su lanza al go- 


\section{3}

Paideia Surcolombiana

bernador español en el grito comunero, las mujeres patriotas que cubrieron la retirada de los libertarios y fueran fusiladas por orden de Sámano, los 17 mil liberales muertos en Matamundo, los campesinos que huyendo de la violencia del 48 fueran a sembrar desamparo en Caquetá y sus alrededores. Nadie resume estas gestas, nadie internaliza ni para la escuela los actos que podrían sembrar raíces identitarias, por lo que vemos en los artistas de la cultura megalítica agustiniana o en Rojas Garrido o en Reynaldo Matiz o en Rivera, sólo manifestaciones aisladas de momentos circunstanciales del terruño y no puntos cimeros de una expresión cultural que ayuda a resistir los embates de la agresión regresiva interna y externa.

Ahora nos vemos compelidos -la guerra resuelta por el Plan Colombia nos volvería epicentro del conflicto-a hablar no de "opitud" y de "huilensidad" (tópicos preclaros del chovinismo opita y falaz), sino de surcolombianidad. Seis regiones que se intentan construir sobre movimientos políticos y culturales divergentes del bipartidismo, buscando arraigo en descubrimientos que amparen su mismidad, para así entroncarse dignamente en el universalismo diverso de la globalización; admiten -seguramente por su situación geográfica privilegiada- al saqueado y desidentificado Huila. Los intentos pueden ser más altos que los viajes a Europa para usar el pretexto de la guerra, tal como puede advertirse tanto en el gobierno del Cauca como en el del Tolima. En nuestro caso no se construye un soporte ciudadano que aliente al gobierno huilense por senderos distintos a la hegemonía bipartidista, que tan irremediablemente nos hunde en los peores índices vitales del país.

Ojalá que el abrigo de otras maneras diferentes y dignas de ver el mundo y el entorno aprendamos a respetarnos, a valorar nuestra tradición de autenticidad y resistencia, buscando conformar unas señas propias que nos particularicen en el cosmos, mediante la indagación que devendrían programas a realizar, en consonancia con la autonomía integral que reclama lo avanzado de nuestro pueblo, ligando asi su singularidad con el suceder universal. Entonces, podríamos superar los indicadores del analfabetismo, insalubridad, desempleo, clientelismo. saqueo de recursos, miseria espiritual y material que al alba del nuevo milenio nos repiten con escarnio ante la faz del país y del mundo.

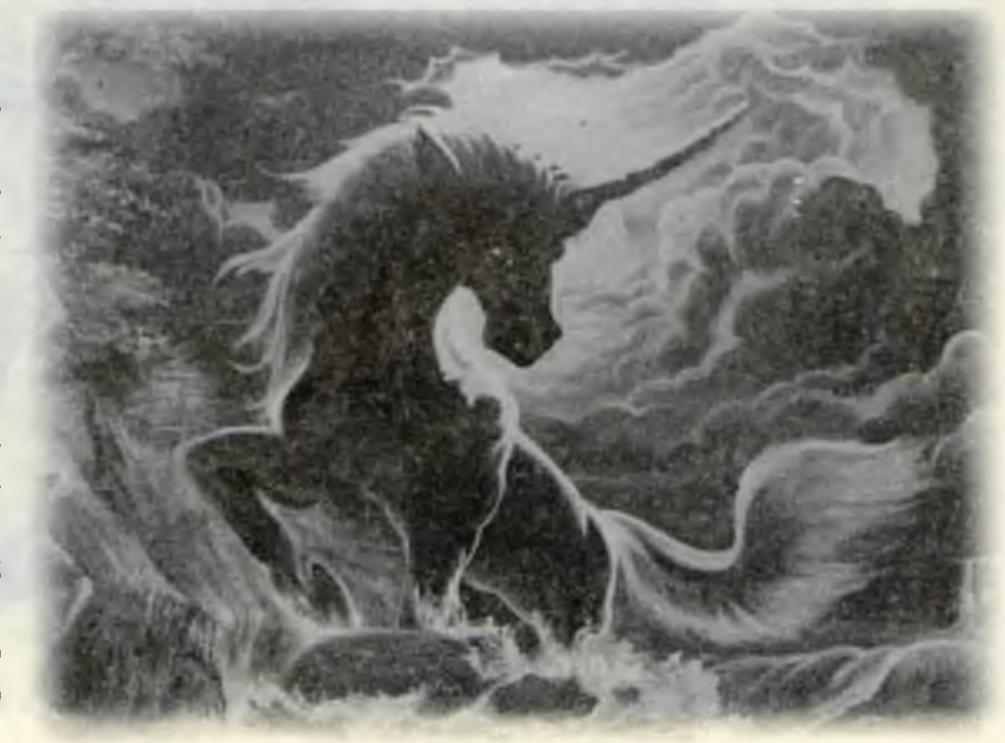




\section{NLIRY ANDREA WLINOZ}

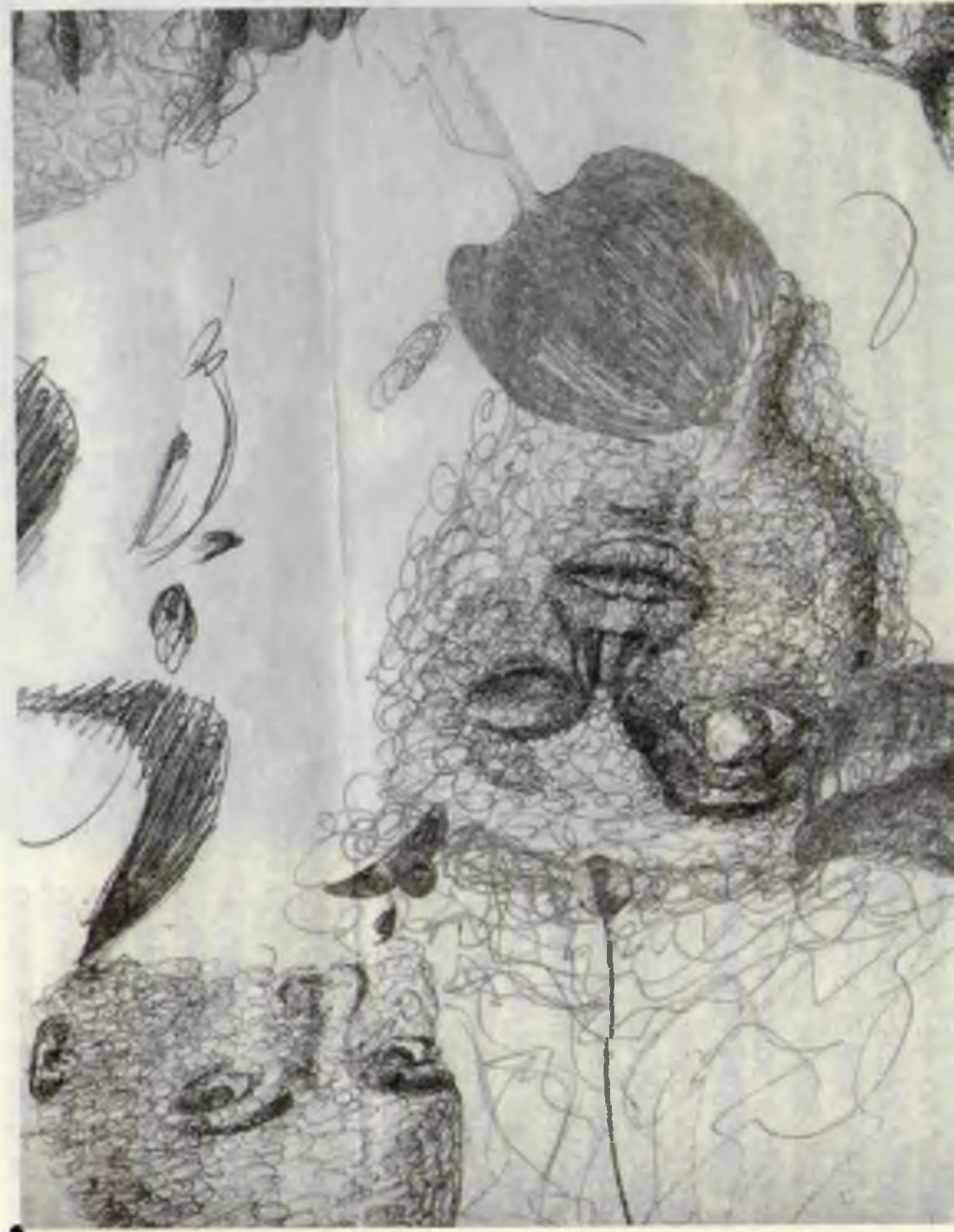




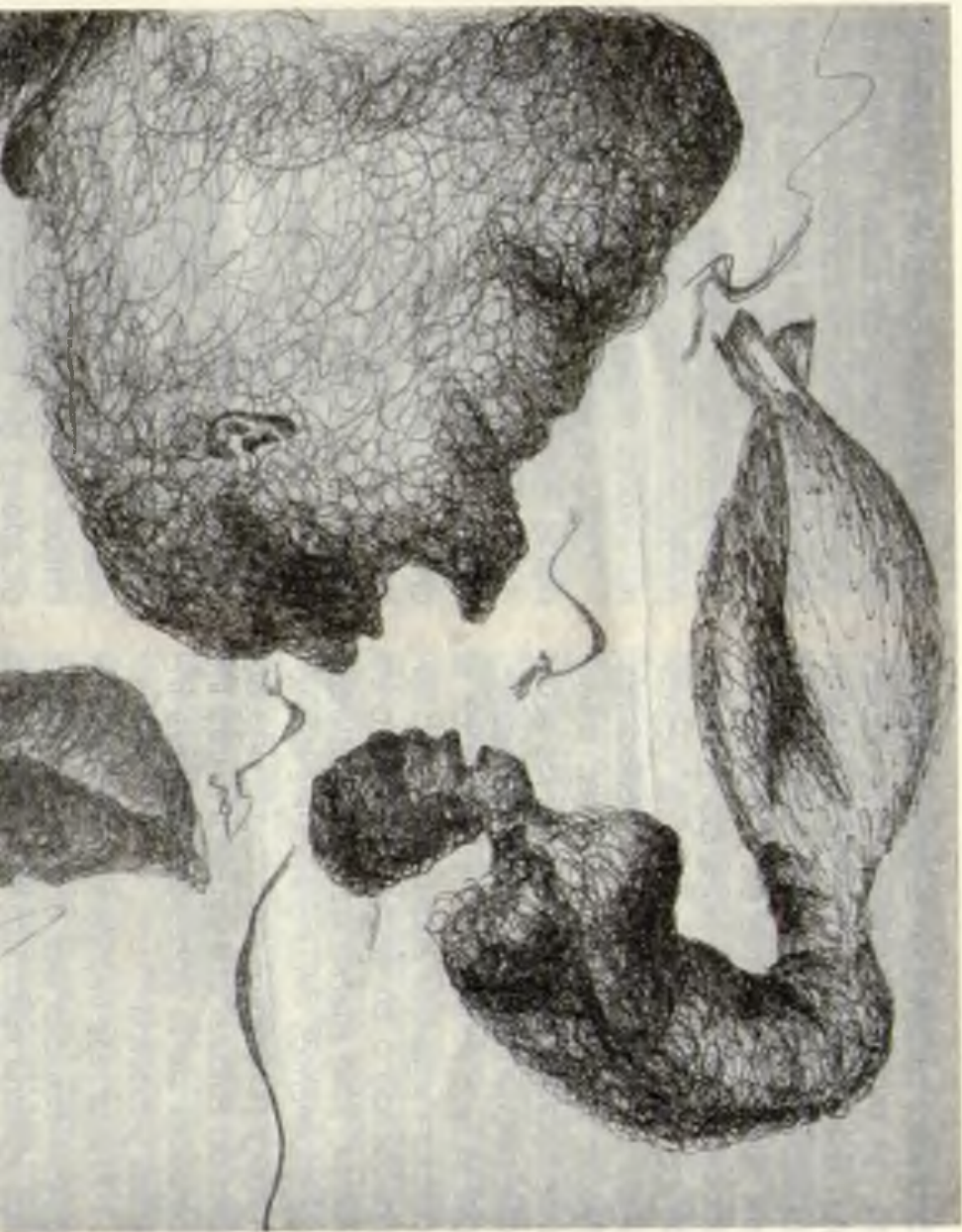

